\title{
Environmental Impact Assessment, on the Operation of Conventional and More Electric Large Commercial Aircraft
}

\author{
R. Seresinhe, C. P. Lawson and R. Sabatini , School of Engineering, Cranfield University, UK
}

\begin{abstract}
Global aviation is growing exponentially and there is a great emphasis on trajectory optimization to reduce the overall environmental impact caused by aircraft. Many optimization techniques exist and are being studied for this purpose. The CLEAN SKY Joint Technology Initiative for aeronautics and Air transport, a European research activity run under the Seventh Framework program, is a collaborative initiative involving industry, research organizations and academia to introduce novel technologies to improve the environmental impact of aviation. As part of the overall research activities, "green" aircraft trajectories are addressed in the Systems for Green Operations (SGO) Integrated Technology Demonstrator.
\end{abstract}

This paper studies the impact of large commercial aircraft trajectories optimized for different objectives applied to the on board systems. It establishes integrated systems models for both conventional and more electric secondary power systems and studies the impact of fuel, noise, time and emissions optimized trajectories on each configuration. It shows the significant change in the fuel burn due to systems operation and builds up the case as to why a detailed aircraft systems model is required within the optimization loop.

Typically, the objective in trajectory optimization is to improve the mission performance of an aircraft or reduce the environmental impact. Hence parameters such as time, fuel burn, emissions and noise are key optimization objectives. In most instances, trajectory optimization is achieved by using models that represent such parameters. For example aircraft dynamics models to describe the flight performance, engine models to calculate the fuel burn, emissions and noise impact, etc. Such techniques have proved to achieve the necessary level of accuracy in trajectory optimization.

This research enhances previous techniques by adding in the effect of systems power in the optimization process.

A comparison is also made between conventional power systems and more electric architectures. In the conventional architecture, the environmental control system and the ice protection system are powered by engine bleed air while actuators and electrics are powered by engine shaft power offtakes. In the more electric architecture, bleed off take is eliminated and the environmental control system and ice protection system are also powered electrically through engine shaft power off takes.

\section{INTRODUCTION}

It is estimated that air transport moves over 2.2 billion passengers annually and that by the year 2050 the current commercial aircraft fleet will be doubled. Moreover, it is expected that within the next 20 years, demand for air travel will increase between $4-5 \%$ per year. [1]

This expected growth in aviation has significant effects on the global environment. Waitz et al. [2] highlights noise, local air quality and climate change as some of the key areas that need to be addressed within the topic of aviation and its impact on the environment.

To realize this challenge, in Europe, the Advisory Council for Aeronautics Research in Europe (ACARE) has set out certain goals which are to be achieved by 2020. Among these, a 50\% reduction of the perceived noise compared to current average noise levels, a $50 \%$ cut in $\mathrm{CO}_{2}$ emissions per passenger kilometer and an $80 \%$ cut in $\mathrm{NO}_{\mathrm{x}}$ emissions are key objectives [3]. Moreover it has identified that more efficient aircraft, more efficient engines and improved air traffic management will be the key contributors to achieving the objectives [1].

In order to address these challenges the European Commission (EC) initiated the Clean Sky program. The program consists of six Integrated Technology Demonstrators (ITDs). In this framework, the Systems for Green Operations (SGO) ITD addresses the novel and more efficient ways of managing aircraft energy, as well as aircraft trajectory and mission.

This research has been conducted under the SGO ITD to study and compare the impact on the environment due to the operation of conventional and more electric aircraft.

\section{REVIEW}

In order to conduct such a study, it was essential to establish key definitions and limitations. In particular, for the purpose of this study, only technology advances in the airframe systems are considered. Hence a conventional aircraft is defined as an aircraft which uses pneumatic, hydraulic and electrical systems comparable to most operational aircraft today.

The More Electric Aircraft (MEA) is defined as an aircraft with all major airframe systems powered electrically. 
A key limitation of the study is that it does not take into account more electric or all electric aircraft engines and it is based on current high by-pass commercial turbofan engine performance.

\section{The conventional aircraft}

The conventional large aircraft has systems run purely on electricity as well as systems requiring electrical power but using pneumatic or hydraulic power as the primary type of power. Hence to get a better understanding of what components are run by which power it is worthwhile to discuss key aircraft systems briefly.

Environmental Control System (ECS) - The ECS carries out the essential functions of ventilation and pressurization as well as thermal regulation. In conventional aircraft the ECS is typically powered by the bleed air extracted from the engines hence it is pneumatically powered [4]. However, certain equipment necessary to maintain the functionality of the ECS are powered electrically. The re-circulation fans, many pressure regulating valves, the monitoring and controlling computers, and a variety of controllers are run electrically.

Ice Protection System (IPS) - The IPS is in charge of providing ice and rain protection. One of the primary concerns for the IPS is the build-up of ice on the wing and the majority of the energy required by the IPS is to carry out wing antiicing. In the conventional large aircraft, the wing anti-icing is typically performed using hot bleed air extracted from the compressor stage of the engines [5]. Hence the primary power is pneumatic power. But for the anti-icing of probes, the wipers, the ice detectors, the anti-icing and de-misting of cockpit windows, and the operation of some valves and most controllers, electrical power is used.

Hydraulic System - The hydraulic system in the conventional large aircraft is tasked with the actuation of flight control surfaces, landing gear retraction and wheel braking. Most components in the system are powered engine driven pumps. But certain equipment such as some hydraulic pumps may be powered electrically. Also controllers and measurement valves in the system are powered electrically. Typically, hydraulic reservoirs are pressurized using engine bleed, thus introducing a pneumatic component as well [6].

Fuel system - It is typical to have electrically powered pumps for engine feed in fuel systems of large conventional aircraft. But it is also common to have jet pumps (which use fuel as the working fluid) to carry out less critical tasks, such as transfers to the outer tanks. The monitoring and measuring systems are also typically powered by electricity [6].

Other systems - Systems such as the lights, navigation, communication, auto pilot, flight control system, indicating and recording, and water and waste systems are typically powered by electricity.

Page 2 of 11
A scheme summarizing the main power sources utilized in conventional large aircraft systems is presented in Figure 1.

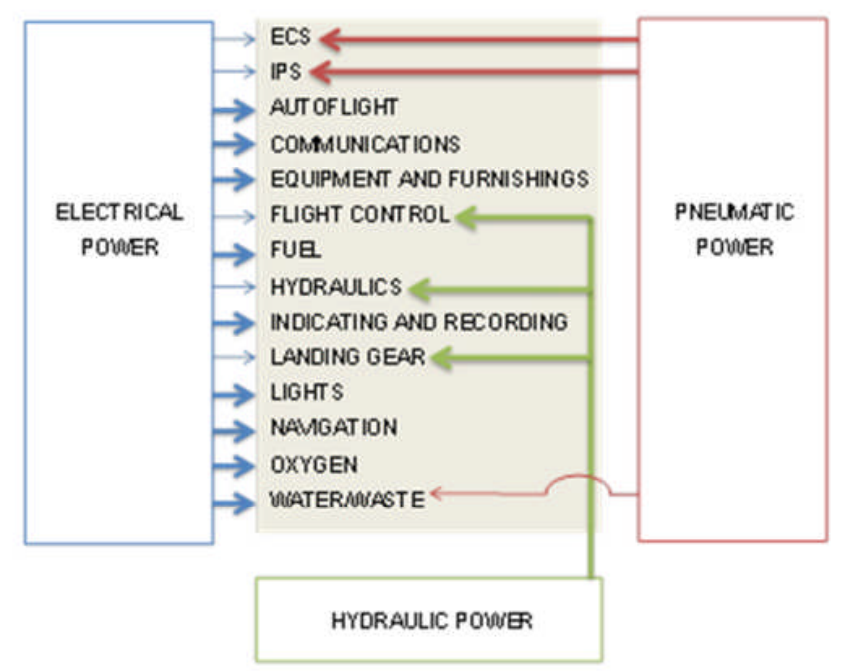

Figure 1: Typical power types in conventional large aircraft systems

\section{The MEA}

The history and the timeline of the development of the MEA concept are well documented in [7]. According to [8] the MEA has a reduced design complexity, reduced parts count and more importantly less environmental impact.

Essentially all the major power users such as the ECS and IPS (which previously used pneumatic power) and the flight control surface actuation (which was powered by the hydraulic systems) are replaced by electrically powered systems.

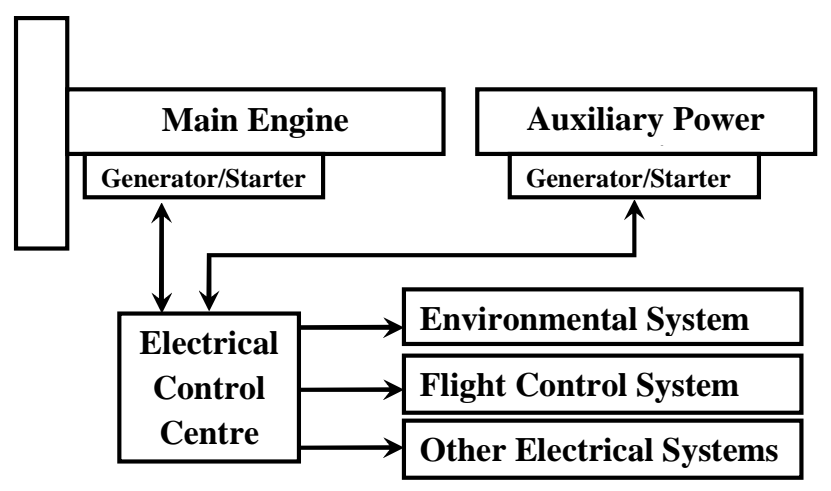

Figure 2: Integrated more electric aircraft systems [8] 


\section{Trajectory and trajectory optimization}

To facilitate the comparison study of conventional and more electric aircraft operations, the study needs to incorporate the operational aspect of aircraft as well.

According to [9] the need for better Air Traffic Management (ATM) is a driver for aircraft trajectory planning and optimization in commercial aircraft. And optimizing the flight trajectory for environmental gains is an important goal and a significant extension of the traditional avionics Flight Management System (FMS) and ATM tasks.

The area of aircraft trajectory optimization has been and is a key research area in Aerospace Engineering and it is also one of the key research topics addressed by the Clean Sky SGO ITD.

Studies such as [10] and [11] provide surveys of trajectory optimization methods and the approach to apply the methods to commercial aircraft trajectory optimization.

There are many techniques and approaches that can be used to generate optimal commercial aircraft trajectories. In general, the trajectory of an aircraft can be optimized for many different objectives such as fuel, time, noise and emissions among others. Typically the trajectory optimization is heavily based on aircraft flight dynamics and performance, engine performance and optimization techniques. However, in most cases, the effects of the aircraft systems are not often included in the optimization loop.

This study does not focus on trajectory optimization techniques as such, but rather focuses on the relationships between globally optimal trajectories and aircraft systems. The objective of the study is to establish the significance of the impact that the aircraft systems have on trajectory optimization and thus the operation of the aircraft.

\section{GREEN AIRCRAFT TRAJECTORIES UNDER ATM CONSTRAINTS $\underline{\text { (GATAC) }}$}

GATAC is the framework that has been developed to model, simulate, optimize and analyze aircraft trajectories within the SGO ITD Management of Trajectory and Mission (MTM) research framework.

The GATAC tool has been discussed in-depth in [12]. The framework allows the user to set-up a flight case by defining initial and final flight points as well as flight constraints. A typical set-up is shown below in Figure 3;

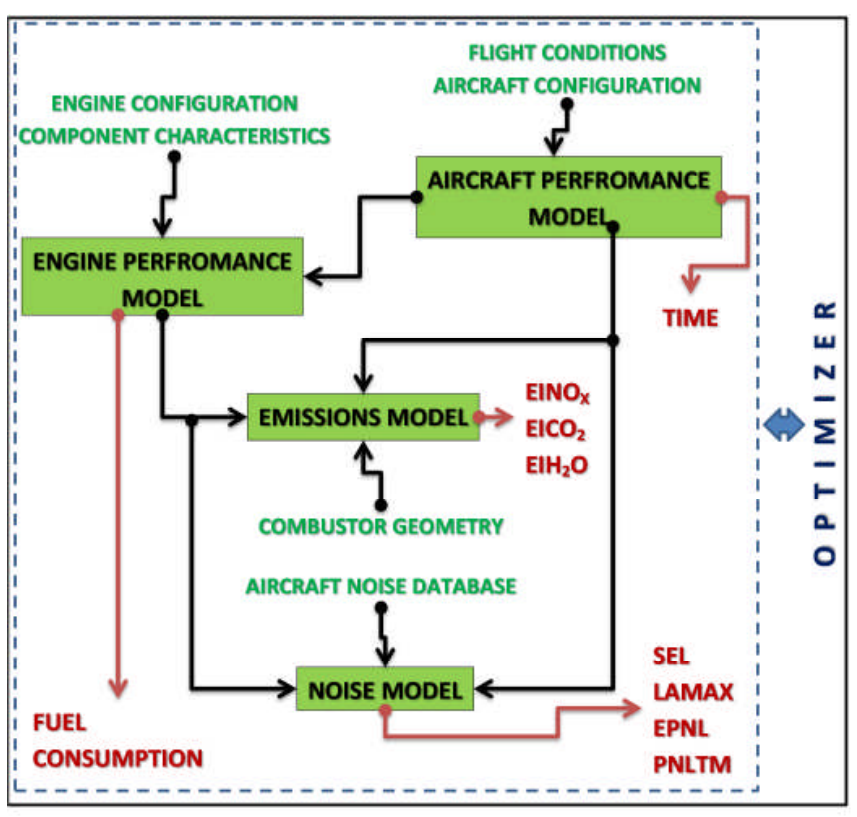

Figure 3: Typical set up in GATAC for trajectory optimization [13]

\section{Case studies}

The baseline aircraft considered in our case studies was a twin engine short range aircraft with a maximum passenger capability of 180 . The baseline engine was a twin spool turbofan engine capable of producing a maximum static takeoff thrust of $121 \mathrm{kN}$ at ISA $+30{ }^{0} \mathrm{C}$.

For the preliminary performance analysis, two test cases were studied [13]:

- Amsterdam Airport Schiphol - Franz Josef Strauss International Airport Munich

- London Heathrow International Airport - Amsterdam Airport Schiphol

All test cases included constraints to represent air traffic management, aircraft performance and engine performance limitations [13].

The results of the trajectory optimization are shown below in Fig. 4 to Fig. 7 for the Amsterdam to Munich and London to Amsterdam cases. 


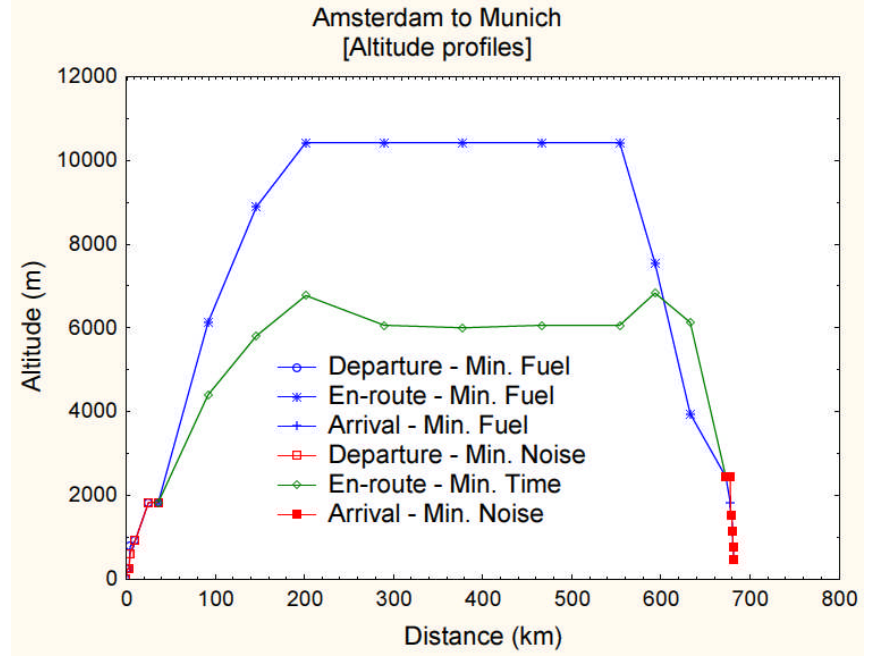

Figure 4: Amsterdam to Munich - altitude profile [13]

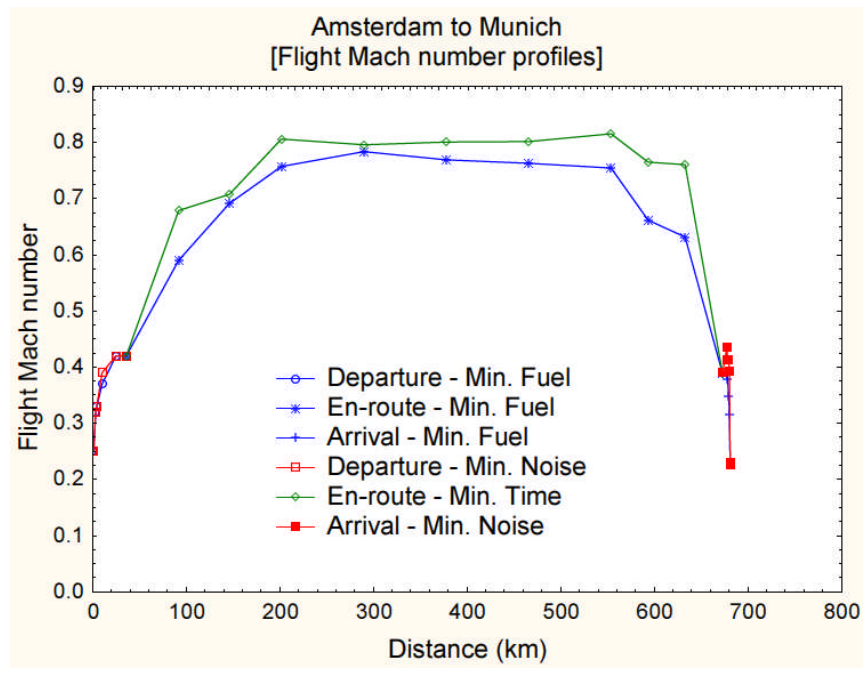

Figure 5: Amsterdam to Munich - flight Mach number profile [13]

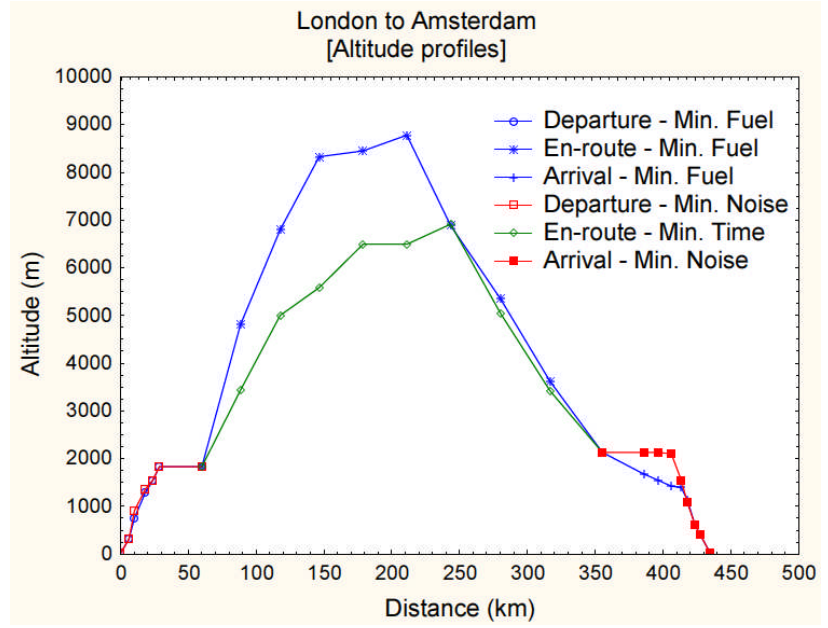

Figure 6: London to Amsterdam - altitude profiles [13]

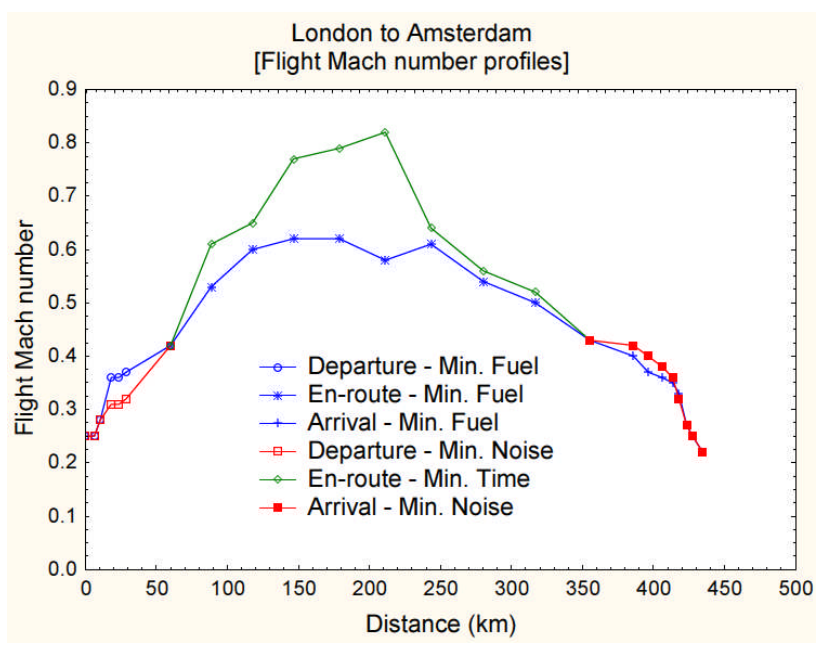

Figure 7: London to Amsterdam - flight Mach number profile [13]

\section{AIRCRAFT SYSTEMS MODEL}

\section{Conventional aircraft systems model}

The conventional aircraft model consisted of a pneumatic ECS, pneumatic IPS, hydraulically actuated control surfaces and the conventional electrics.

The specification and the description for the aircraft systems model are documented in [14] and [15].

The pneumatic ECS model was validated as per data in [16], the IPS model was verified as per [17] and the electrical model was validated at a systems level by using [18] and at an aircraft level using [19] and [20].

\section{MEA systems model}

The MEA systems model consisted of an electric ECS, electrical IPS, electrical actuators for flight controls and the conventional electrical loads.

The electrical ECS was validated by using data in [4] and the conventional electrical load was calculated by the electrical model mentioned above.

The loads for the electrical IPS and the electrical actuators were estimated as per [21].

This study used the trajectory data shown previously, to assess the impact on the aircraft systems operation. 


\section{RESULTS}

\section{Conventional aircraft}

By using the results obtained from the trajectory optimization study, the conventional aircraft systems model was simulated and the results were analyzed. The electrical generator was simplified by using a constant efficiency of $85 \%$.

The results obtained for the London to Amsterdam case are shown in Fig. 8 to Fig. 11.

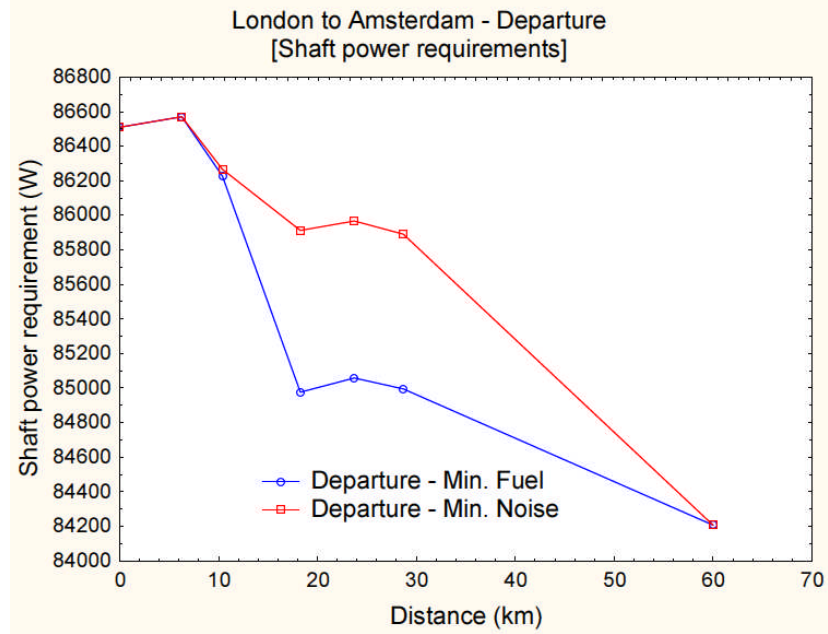

Figure 8: London to Amsterdam - departure - shaft power variation

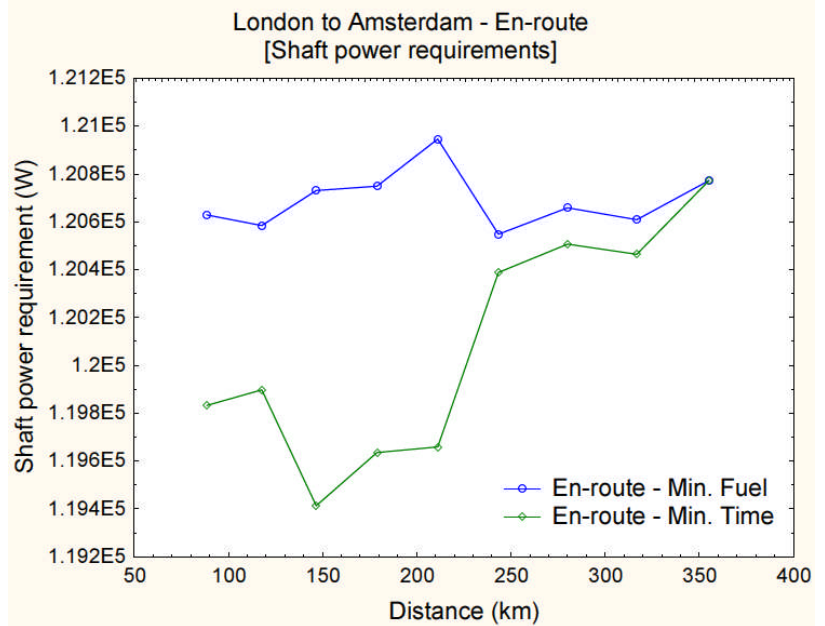

Figure 9: London to Amsterdam - en-route - shaft power variation

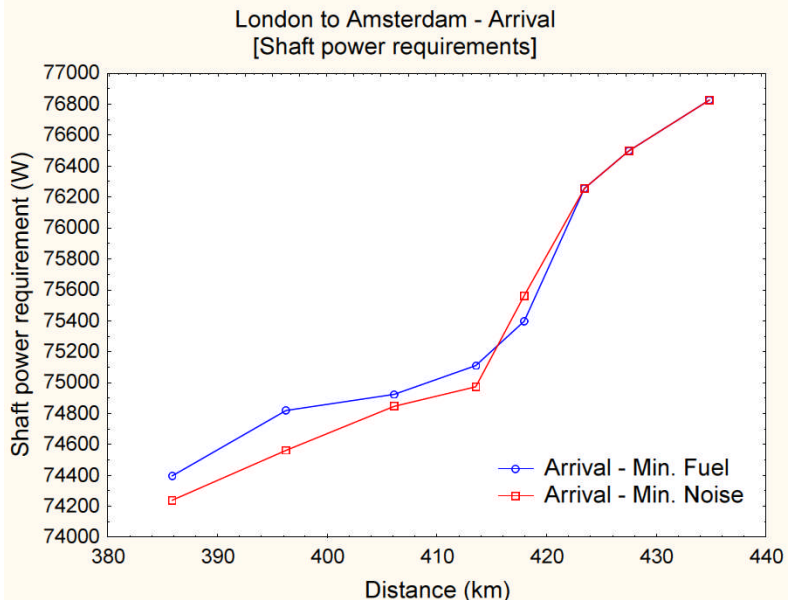

Figure 10: London to Amsterdam - arrival - shaft power variation

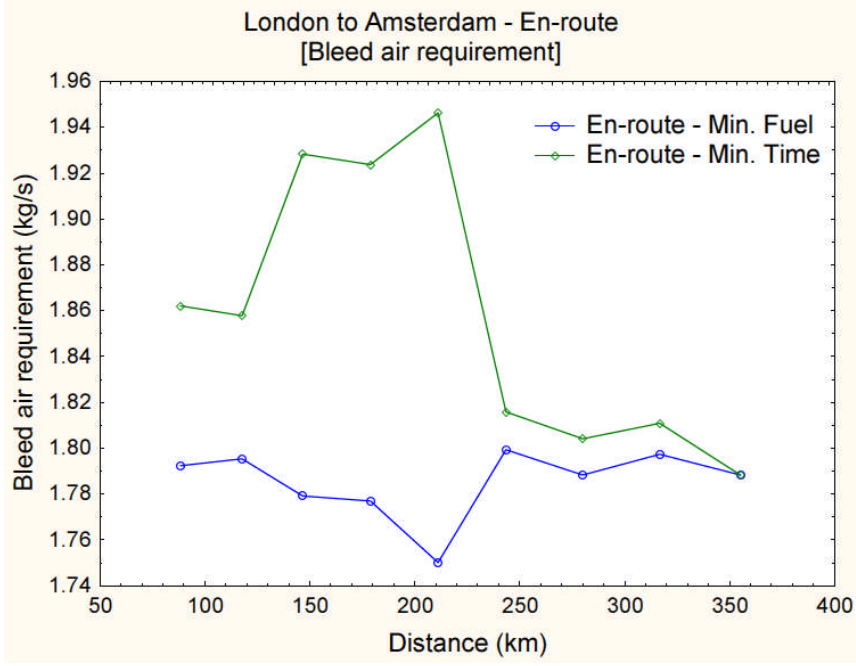

Figure 11: London to Amsterdam - en-route - bleed air requirement

It was observed, that the shaft power requirements and bleed air requirements vary depending on flight conditions. But the magnitude of the variation was small. Therefore, it was concluded that the change in fuel penalty due to off-takes would not significantly affect the gains between the various optimization objectives. Moreover even though Figure 11 shows that the bleed air requirement is sensitive to the flight conditions, in real aircraft engine operation the bleed rates are usually fixed for different flight phases. 
Similar effects can be observed for the Amsterdam to Munich case (Fig. 12 and Fig. 13).

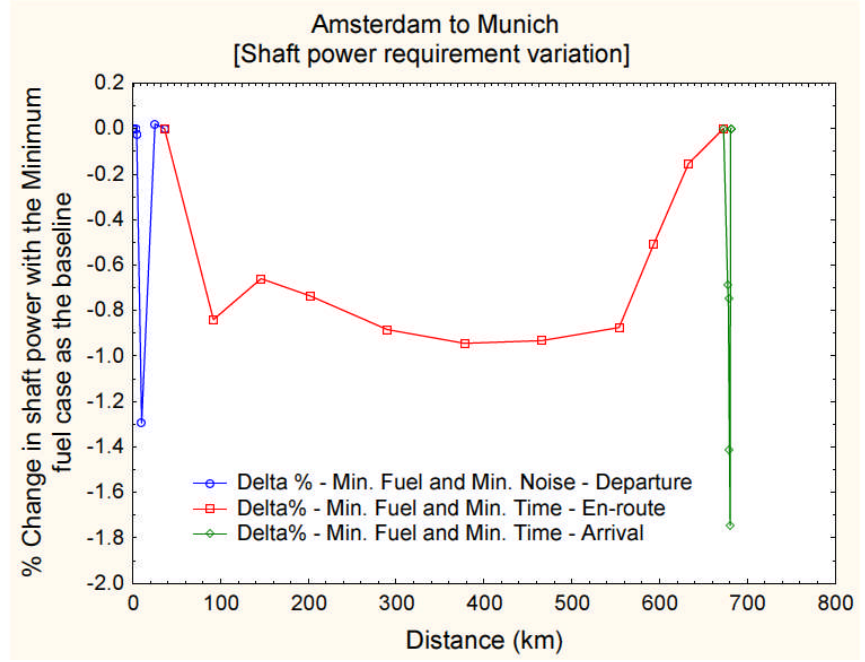

Figure 12: \% Change in the shaft power requirement with the minimum fuel trajectory as a baseline

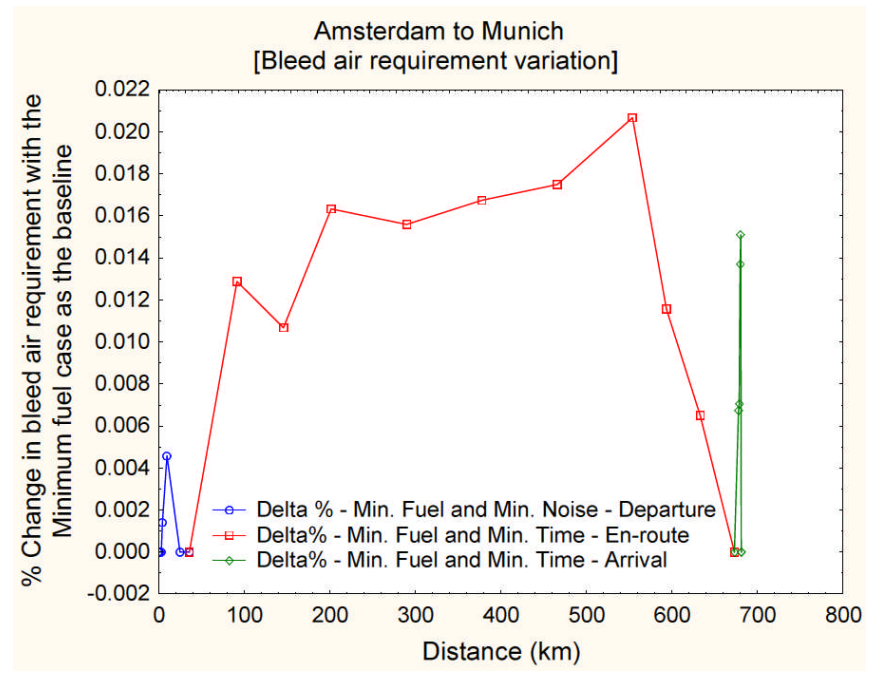

Figure 13: \% Change in the bleed air requirement with the minimum fuel trajectory as a baseline

Both cases showed similar trends for both shaft power and bleed air requirements. It was interesting to note from Figure 8, that for the London to Amsterdam case the minimum noise case has the higher demand at departure. But from Figure 12 (Amsterdam to Munich case), the minimum fuel trajectory has a greater demand in shaft power. This disparity clearly shows that the influence of the trajectory on the systems is quite complex and a multi-disciplinary study such as this is needed to understand the complexities.

Yet on the other hand, all results for the conventional aircraft systems showed that the magnitude of the change in shaft power or bleed air requirements respective to each trajectory are small. Therefore, it can be concluded that the conventional Page 6 of 11 aircraft systems off-takes would not affect the trajectory optimization significantly.

\section{MEA}

A more interesting scenario was the MEA which, due to the peculiarities of the technical approach adopted, showed an entirely different perspective of aircraft systems impacts on optimal flight trajectories.

The following assumptions were adopted in order to simulate the MEA systems:

- Any flight point within the threshold of $4572 \mathrm{~m}$ and $6706 \mathrm{~m}$ is likely to have severe icing conditions and the IPS will be fully operational.

- By using the $80 / 20$ rule it was estimated that the average power for flight control actuation would be $36 \%$ of the peak power [22].

The results of the MEA analysis for the London to Amsterdam case are shown in Fig. 14 to Fig. 17.

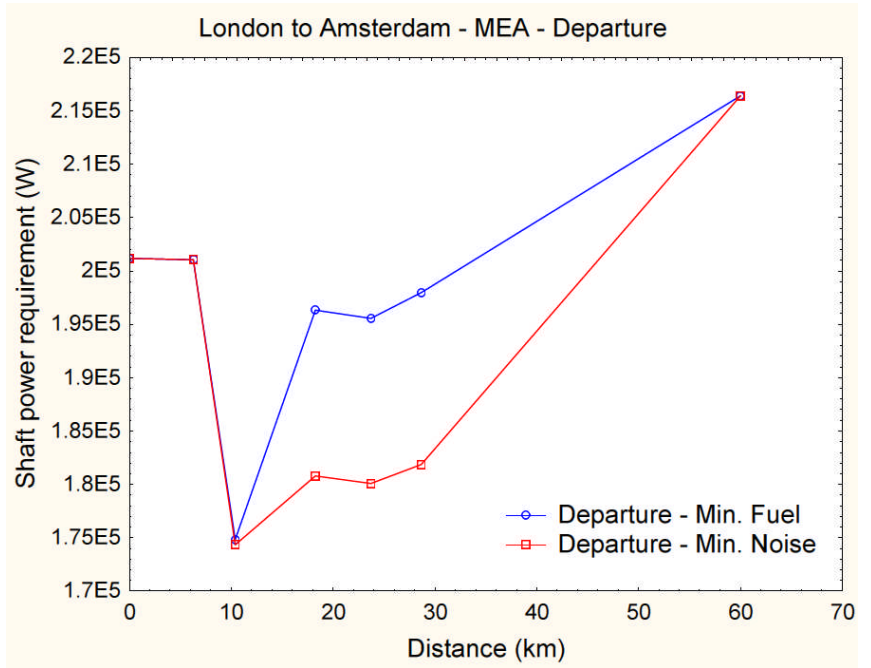

Figure 14: Shaft power requirement for London to Amsterdam - MEA - Departure 


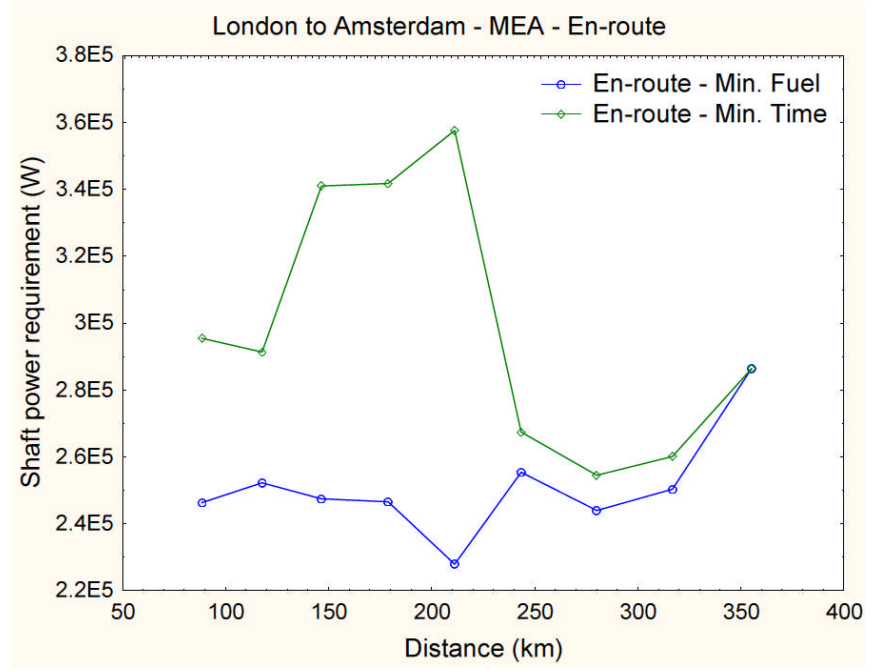

Figure 15: Shaft power requirement for London to Amsterdam - MEA - En-route

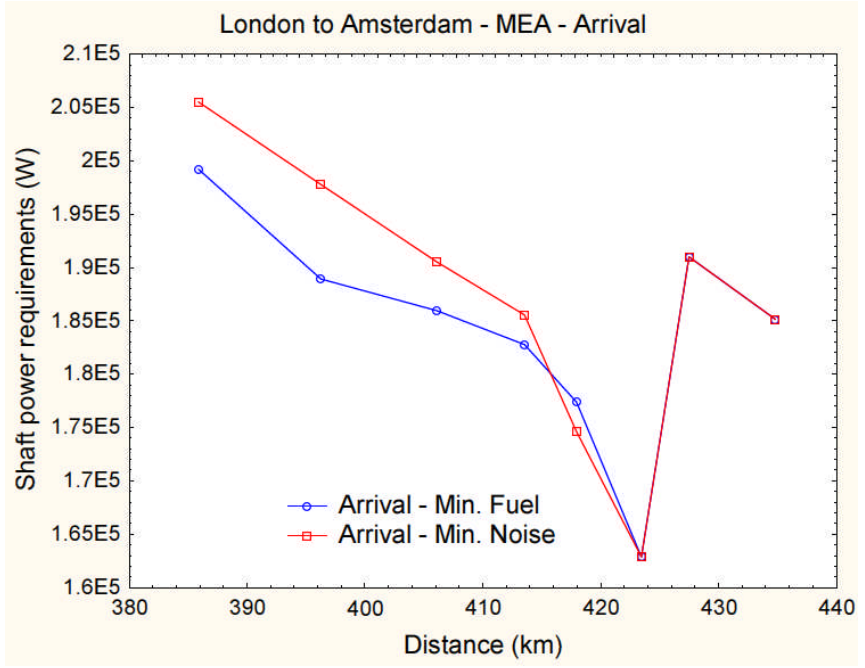

Figure 16: Shaft power requirement for London to Amsterdam - MEA - Arrival

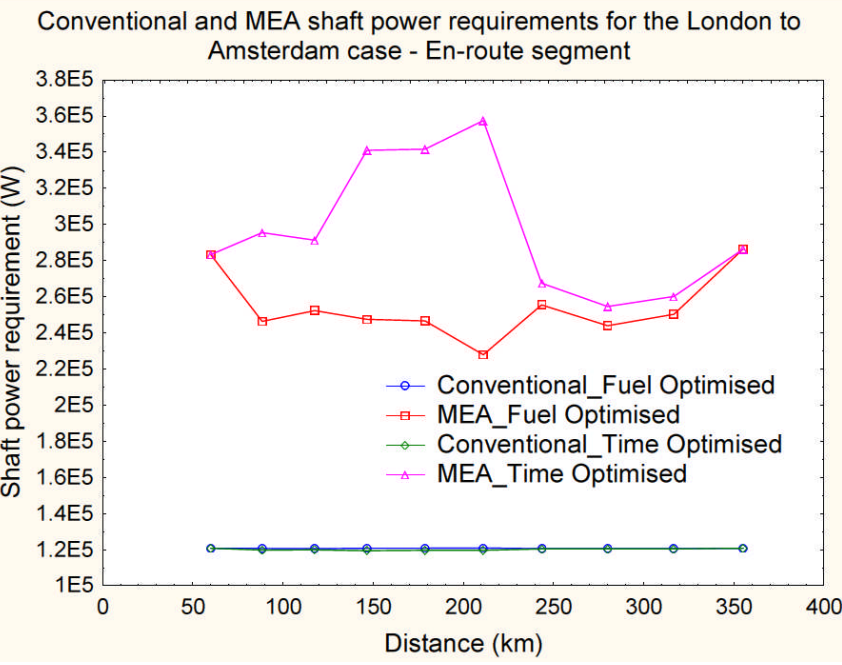

Figure 17: Increase in the shaft power requirement compared to the conventional aircraft for the London to Amsterdam case

As expected, there was a significant increase in the electrical load. The major contributors were the electrical ECS and the IPS. Moreover it was also observed that during the en-route segment, where the aircraft operates for a majority of the time, the differences in the effects of the applied optimization criteria were significant.

From Figure 17 it is observed that the MEA showed an average increase of $110 \%$ over the conventional aircraft for the en-route segment when the trajectory was optimized for fuel burn (i.e., minimum fuel consumption). When the trajectory was optimized for time (i.e., minimum flight time), the increase was about $148 \%$. Moreover, the difference in the shaft power requirement, between the fuel and time optimized trajectories was about $18 \%$, whereas in the conventional aircraft, the shaft power requirements changed only by about $0.4 \%$ between the fuel and time optimized en-route segments. However, it should be noted that these figures only represent the shaft power requirements and that the total secondary power requirements for the conventional aircraft must include the primary pneumatic loads as well. For this particular aircraft, during the en-route segment, the pneumatic ECS power consumption was estimated in the order of $330 \mathrm{~kW}$ to $360 \mathrm{~kW}$.

There are some key characteristics that were observed:

- The total secondary power requirement for the conventional aircraft was higher than the MEA.

- The MEA shaft power requirement was much greater than the conventional shaft power requirement.

- The total power requirements did not vary greatly with respect to the trajectory, in the conventional aircraft. 
- The total power requirement, even though less than the conventional aircraft (yet still significant), varied significantly with respect to the trajectory, in the MEA.

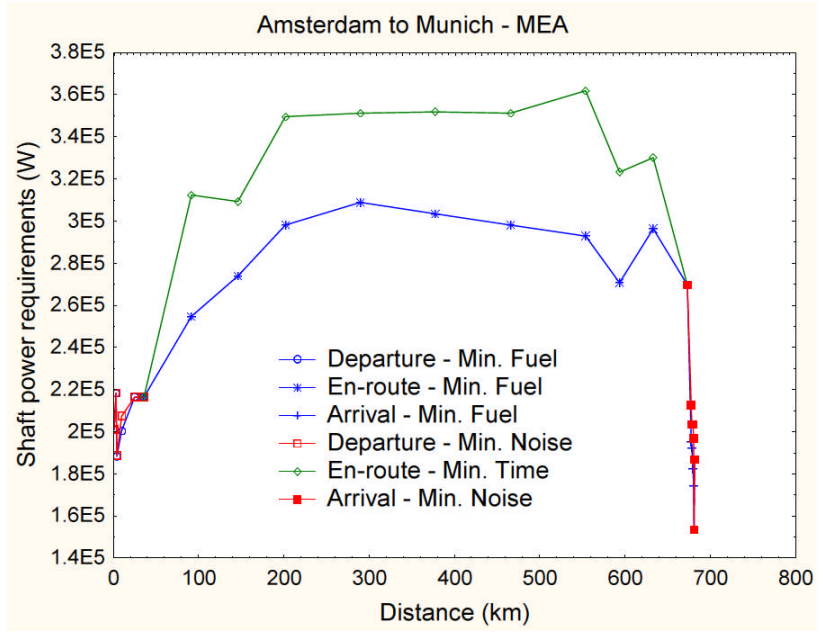

Figure 18: Shaft power requirement for Amsterdam to Munich - MEA

Conventional and MEA shaft power requirements for the Amsterdam to

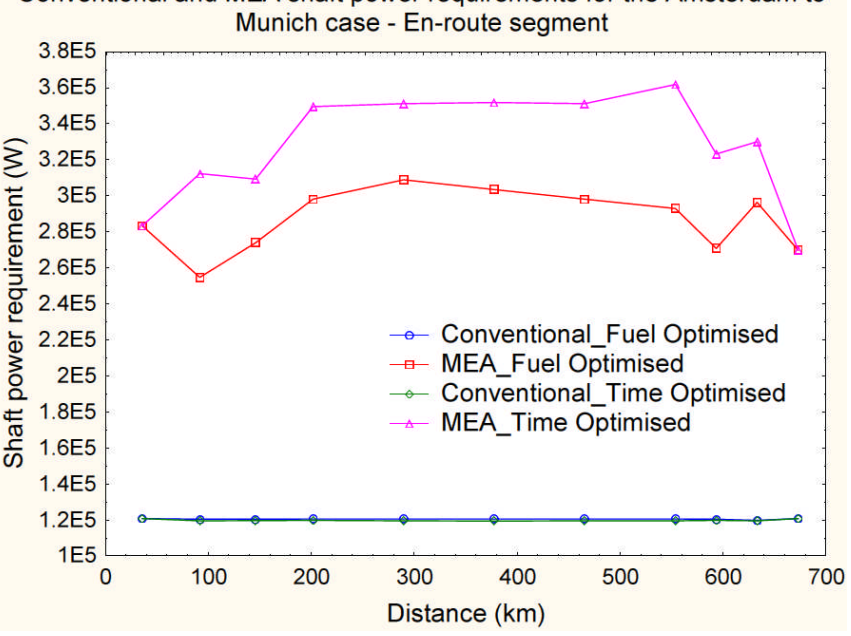

Figure 19: Increase in the shaft power requirement compared to the conventional aircraft for the Amsterdam to Munich case

For the Amsterdam to Munich case, it was observed that the average increase in the shaft power requirement during the enroute segment for the fuel optimized trajectory compared to the conventional aircraft was $138 \%$, while in the time optimized trajectory there was an average increase of $173 \%$. Moreover, in the MEA configuration the change in the shaft power requirement between the fuel optimized and time optimized trajectories was about $14 \%$ while in the conventional configuration it was only $0.6 \%$.
As in the London to Amsterdam case, the primary pneumatic loads were estimated and were between $330 \mathrm{~kW}$ to $360 \mathrm{~kW}$. Similar characteristics were observed for this case as well.

An en-route flight trajectory currently flown by many aircraft, between Heathrow and Schiphol was also considered, in order to benchmark the increases in the shaft power requirement due to trajectory. The trajectory profiles are listed in [13].

The results of this additional case study are shown in Fig. 20.

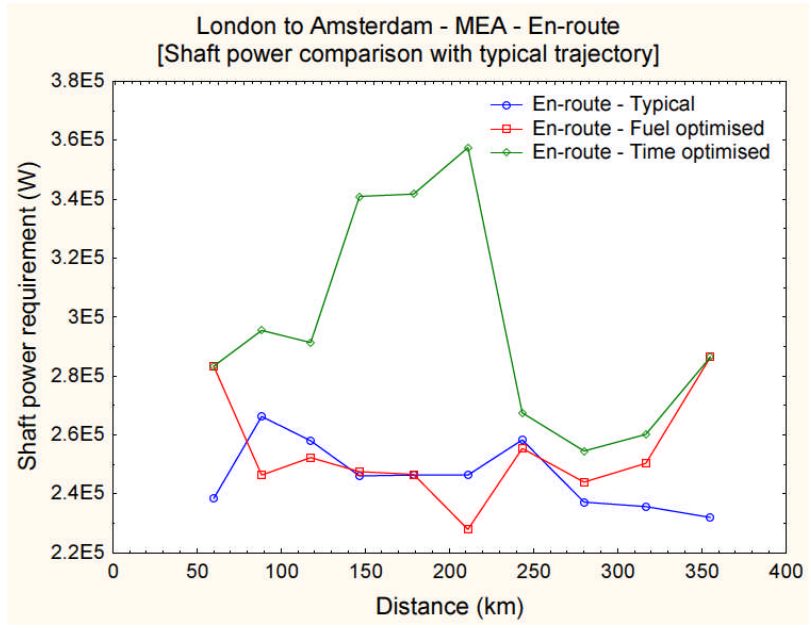

Figure 20: Comparison of MEA power requirement for typical, fuel optimized and time optimized trajectories for the London to Amsterdam en-route segment

It was observed that the fuel optimized and time optimized trajectories had different shaft power requirements in comparison to a typical trajectory. The magnitude of the change was significant, more so for the flight time is optimized. Moreover it is expected that by accounting for the power off-take penalty due to systems, a better comparison of the trajectories can be made and thus a better assessment of the environmental impact due to aircraft operation.

\section{CONCLUSION}

This paper presented an initial study on the effects of aircraft systems on trajectory optimization processes and vice-versa. In addition to conventional systems, it presented the MEA as a case where the systems have significantly higher power offtake demands of varying magnitudes during the different flight phases. The significant change in the fuel burn has an important effect on MEA trajectory optimization studies. The main conclusion is that the optimality of the computed aircraft trajectories can be significantly improved by representing the aircraft systems requirements within the optimization loop, particularly for MEA applications. 


\section{FURTHER WORK}

As an extension of the work, it is planned to use the GATAC framework within the Clean Sky program to study trajectory optimization with both conventional and more electric aircraft systems. Moreover an analysis is being carried out to investigate how an holistic approach to aircraft design (including all on-board systems) affects aircraft operations and vice versa.

\section{REFERENCES}

1. Clean Sky. Aviation \& Environment. Clean Sky. [Online] [Cited: March 13, 2013.]

http://www.cleansky.eu/content/homepage/aviation-

environment.

2. Waitz, Ian, et al. Report to the United States Congress AVIATION AND THE ENVIRONMENT - A National Vision Statement, Framework for Goals and Recommended Actions. MIT.edu. [Online] [Cited: March 13, 2013.] http://web.mit.edu/aeroastro/partner/reports/congrept_aviation _envirn.pdf.

3. Arguelles, P, et al. EUROPEAN AERONAUTICS: A VISION FOR 2020 - Meeting society's needs and winning global leadership. Luxembourg : European Commission, 2001.

\section{ELECTRIFICATION OF THE ENVIRONMENTAL CONTROL SYSTEM. Herzog, Jacques. s.1. : ICAS 2006, 2006.}

5. An Electric Deicing System for Aircraft. Giloy, E.W. 2, s.1. : AIEE, 1949, Transactions of the American Institute of Electrical Engineers, Vol. 68. ISSN: 0096-3860.

6. Moir, Ian and Seabridge, Allan. Aircraft Systems Mechanical, electrical, and avionics subsystems integration. s.1. : John Wiley \& Sons, 2008. ISBN:978-0-470-05996-8.

7. The More Electric Aircraft: the past and the future? R.I.Jones. s.1. : IEE, 1999. IEE Colloquium on Electrical machines and Systems for More Electric Aircraft.

8. POWER-by-wire aircraft secondary power systems. Feiner, Louis J. s.1. : AIAA/IEEE, 1993. AIAA/IEEE - Digital Avionics Systems Conference.

9. In search of the future of air traffic control. T.S.Perry. 8, s.l. : IEEE, 1997, IEEE Spectrum, Vol. 34.

10. Survey of Numerical Methods for Trajectory Optimization. Betts, John T. 2, s.1. : AIAA, 1998, Journal of Guidance, Control and Dynamics, Vol. 21.

Page 9 of 11
11. Application of Direct Transcription to Commercial Aircraft Trajectory Optimization. Betts, John T and Cramer, Evin J. 1, 1995, Journal of Guidance, Control and Dynamics, Vol. 18.

\section{A GENERIC FRAMEWORK FOR MULTI-PARAMETER OPTIMIZATION OF FLIGHT TRAJECTORIES. Chircop,} Kenneth, et al. s.l. : ICAS, 2010.

13. Hartjes, Sander, et al. Systems for Green Operations (SGO) ITD - Report on the Performance Analysis of the Trajectories - Cycle 1 - WP3.2. s.1. : Clean Sky - SGO ITD (Internal), 2012.

14. Cooper, M, et al. Aircraft Systems Modelling Specification Document - WP3.1:O_3.1_40_a. s.1. : Clean Sky - SGO ITD (Internal), 2012.

15. Seresinhe, Ravinka. Aircraft Systems Model - Description Document - WP3.1:O_3.1_40_b. s.1. : Clean Sky - SGO ITD (Internal), 2012.

16. Hocking, M. Passenger aircraft cabin air quality: trends, effects, societal consts, proposals. s.1. : PMID, 2001. PMID:10819229.

17. SAE Aerospace. Ice, Rain, Fog, and Frost Protection AIR1168/4. s.1. : SAE International, 1990.

18. Design of Boeing 777 electric system. Andrade, Luiz and Tenning, Carl. 7, s.1. : IEEE, 1992, IEEE Aerospace and Electronic Systems Magazine, Vol. 7.

19. Airbus. Airbus A300 Engineering Notes Edition 2 Volume 2. s.l. : Airbus, 1975.

20. Lockheed - California Company. Engineering Description Series - Volume 7, Electrical, L-1011. s.1. : Lockheed - California Company, 1970.

21. Power-by-wire aircraft secondary power systems. Feiner, Louis J. s.1. : AIAA/IEEE, 1993. AIAA/IEEE Digital Avionics Systems Conference.

22. Test Results of Reflux-Cooled Electromechanical Actuator. Schneider, M.G, et al. s.l. : SAE, 1994. SAE 942176.

\section{ACKNOWLEDGMENTS}

This work has been carried out as part of collaboration between members and associate members involved with GATAC in the SGO ITD of Clean Sky. The authors wish to acknowledge, in particular, the contributions of Dr. Irfan Madani, Sander Hartjes, Daniele Quaglia, Michael Cooper and Ahmed Shinkafi in this work. The project is co-funded by the 
European Community's Seventh Framework Programme (FP7/2007-2013) for the Clean Sky Joint Technology Initiative.

Page 10 of 11 


\section{DEFINITIONS/ABBREVIATIONS}

\begin{tabular}{|l|l|}
\hline ACARE & $\begin{array}{l}\text { Advisory Council for Aeronautics Research } \\
\text { in Europe }\end{array}$ \\
\hline $\mathbf{C O}_{2}$ & Carbon Di-oxide \\
\hline EC & European Commission \\
\hline ECS & Environmental Control System \\
\hline GATAC & $\begin{array}{l}\text { Green Aircraft Trajectories under Air } \\
\text { Traffic management Constraints }\end{array}$ \\
\hline
\end{tabular}

\begin{tabular}{|l|l|}
\hline IPS & Ice Protection System \\
\hline ITD & Integrated Technology Demonstrator \\
\hline MEA & More Electric Aircraft \\
\hline MTM & Management of Trajectory and Mission \\
\hline NO $_{\mathbf{X}}$ & Nitrous Oxides \\
\hline SGO & Systems for Green Operations \\
\hline
\end{tabular}

Page 11 of 11 